\title{
CPX-351 (VyxeosR) can cause severe rash in acute myeloid leukaemia - a case report
}

Ruth-Maria Urbantat ${ }^{1}$, Valentin Popper ${ }^{1}$, Elisabeth Menschel $^{1}$, Michael Pfeilstoecker ${ }^{1}$, Ernst Forjan ${ }^{1}$, Alexander Nader ${ }^{1}$, Caroline Sieghart ${ }^{1}$, Felix Keil ${ }^{1}$, and Elisabeth Koller ${ }^{1}$

${ }^{1}$ Hanusch Hospital

July 30, 2020

\section{Abstract}

CPX-351 is a promising new therapeutic option for patients with treatment related (tAML) or secondary acute myeloid leukemia (sAML). It exceeded classic $7+3$ therapy in overall survival (OS) and complete remission rates (CR) while providing a similar risk profile. Until now, this sub-group of AML patients had a worse overall

\section{Hosted file}

Main document, vyxeos, skin rash, urbantat etal.pdf available at https://authorea.com/users/ 347471/articles/473147-cpx-351-vyxeos-can-cause-severe-rash-in-acute-myeloid-leukaemiaa-case-report

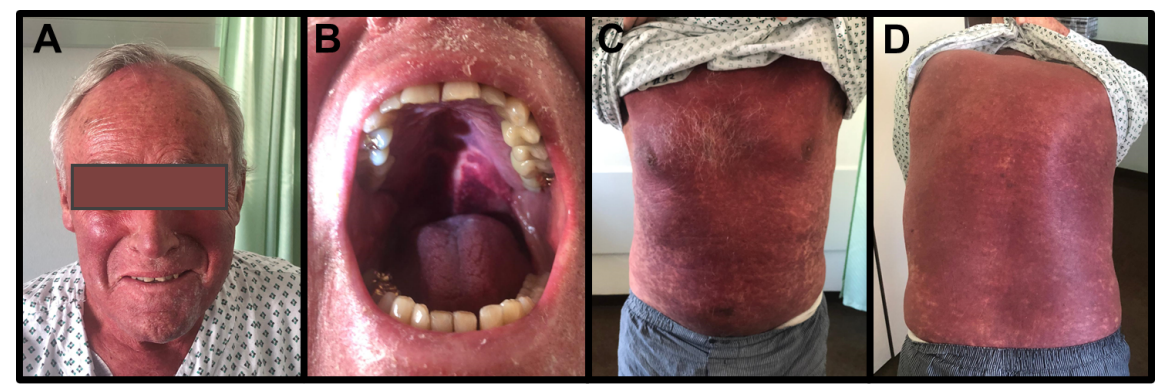

